\title{
En los cuarenta años de Diánoia*
}

\author{
Fernando Salmerón
}

E

1 aniversario - cuando se trata de un plazo razonablemente largo-, de una publicación periódica; o la muerte - aunque se trate de una muerte temprana-, son siempre ocasión propicia para estudios o reflexiones. Los cuarenta años de Diánoia, que nos reúnen esta tarde, son ciertamente un plazo razonable. Sin embargo, no me propongo ahora sino sugerir alguna de esas diversas posibilidades de estudio y señalar su interés.

La perspectiva sociológica siempre es pertinente como condición previa para cualquier intento de considerar el contenido de una publicación periódica, pero su importancia es más notable si se dan dos circunstancias que no concurren en Diánoia: la frecuencia en la periodicidad de la publicación y la apertura o variedad disciplinaria. La apertura hace más amplio el arco de los temas que se discuten en una revista; y la frecuencia en la periodicidad la obliga a estar alerta ante los problemas del día. Pero Diánoia ha sido, desde su primera aparición en marzo de 1955, un anuario; y además se ha consagrado, también desde su origen, a una sola disciplina: la filosofía. En tales condiciones, lo que importa en primer término es atender al contenido.

En este sentido, se puede afirmar sin riesgo, que Diánoia es la primera publicación periódica especializada en filosofía que se intentó en México -no solamente la de más larga vida. Durante cuarenta años, el anuario ha sido impreso sin interrupción por el Fondo de Cultura Económica con rigurosa puntualidad -que apenas en un par de ocasiones excepcionales sufrió un leve retraso. Y su dirección ha estado a cargo del Instituto de Investigaciones Filosóficas. Después de 1955 han surgido otras revistas especializadas en filosofía, algunas patrocinadas por universidades privadas, otras publicadas en provincia -hasta la más reciente (Isonomía) que es especializada en una sola rama de la filosofía (la filosofía del derecho). El propio Instituto de Investigacio-

* Reunión celebrada en la Facultad de Filosofía y Letras de la UNAM, el 28 de mayo de 1996 . 
nes Filosóficas patrocina Crítica desde 1989, otra revista de filosofía, de características distintas a Diánoia.

La descripción de este programa de publicaciones actuales podría ser un primer paso, realmente objetivo, para exponer la situación de la vida filosófica mexicana de fin de siglo, mucho más diversa por cierto que la de hace cuatro décadas, si tenemos presente el comienzo de Diánoia. Pero parece preferible detenerse no en los años actuales, sino precisamente en los anteriores a la aparición de los primeros volúmenes del Anuario, porque será más fácil, en contraste con ellos, comprender lo que la nueva publicación proponía como novedad.

He dicho que Diánoia fue, en su momento, la primera publicación especializada en filosofía, pero no nació sin antecedentes. Y aunque no sea posible referirse a todos, parece indispensable nombrar al menos a los más cercanos. Como revista de filosofía, aunque abierta a muchos otros temas de ciencia y de educación, ya no tiene lugar, entre los antecedentes de Diánoia, la Revista Positiva, que empezó a aparecer en 1901 y cuyos últimos números se publicaron 14 años después, coincidiendo con los años más violentos de la Revolución mexicana. Si bien la revista reprodujo algunos escritos polémicos de Vasconcelos y de Antonio Caso - este par de miembros jóvenes de la generación del Ateneo representaba justo la crítica del positivismo y el fin de la revista.

Los años posteriores a los más violentos de la Revolución vieron surgir grandes revistas literarias, en las que siempre tuvo un lugar la reflexión filosófica y su historia, pero de ninguna de ellas podría decirse que diera a la filosofía un sitio preferente. Aunque alguna llegara a publicar números monográficos sobre temas o corrientes filosóficas, al comienzo de la década de los años cuarentas.

Los verdaderos antecedentes de Diánoia son, en primer lugar, una modesta organización de discusiones filosóficas; en segundo lugar, sus empresas editoriales cumplidas con el apoyo de la Facultad de Filosofía y Letras. No voy a relatar la historia de esa organización de discusiones filosóficas cuyo espléndido desarrollo posterior es de todos conocido, y cuyos primeros pasos fueron descritos con gran detalle por su fundador, Eduardo García Máynez, en un texto publicado en Diánoia en 1966. El ahora Instituto de Investigaciones Filosóficas surgió como un Centro de la Facultad de Filosofía en agosto de 1940, para agrupar a los profesores interesados en escribir, discutir y publicar trabajos filosóficos. Su primera empresa editorial fue el Boletín Bibliográfico, cuyo propósito era publicar los trabajos de los socios y las actas de las discusiones, además de reseñas de libros. El primer número del Boletín apareció en octubre del mismo año de 1940, y el último, al terminar el año de 1943. Para esta fecha, las actividades del grupo habían estimulado a los profesores de otras especialidades y el mismo fundador del Centro, entonces director de la Facultad de Filosofía, inició en 1941 la publicación de una revista como órgano de toda la 
Facultad. Dividida en tres secciones, bien equilibradas, cada una se dividía a su vez en tres partes, para separar los artículos, las notas y las reseñas, la nueva publicación agrupaba los trabajos de filosofía; los de letras; y los de historia y antropología. Y su edición iba acompañada además de un Registro Bibliográfico, como cuaderno independiente, a cargo del profesor Agustín Millares Carlo.

García Máynez fue director de la revista Filosofía y Letras, en un primer periodo, desde 1941 hasta 1946. Eduardo Nicol lo acompañó como secretario. Pero, curiosamente, a partir del número 23, correspondiente al trimestre de julio a septiembre de 1946, en que Agustín Yáñez se hizo cargo de la dirección de Filosofía y Letras, el equilibrio se rompió y desaparecieron las tres secciones iniciales rebasadas por una abundancia de artículos y reseñas filosóficas. No desaparecieron por completo los textos de letras y de historia, pero fueron cada vez menos en número y en muchas entregas de la revista estuvieron ausentes por completo. La revista había dejado de responder a la composición de la Facultad y había venido a convertirse, fundamentalmente, en una publicación filosófica. La publicación por excelencia de la disciplina entre 1941 y 1958, en que se imprimió por última vez.

Lo menos que cabría decir de Filosofía y Letras es que, en sus diecisiete años de vida constituyó la publicación más representativa de la actividad filosófica de México; aunque otras revistas de más amplios intereses culturales Cuadernos Americanos, por ejemplo-, recogieron también textos de especial significación. La simple lectura de los índices de la revista de la Facultad descubre algo de lo que podría rendir el análisis cuidadoso de su contenido: están presentes en ella todavía los miembros de la generación del Ateneo Caso, Reyes y Vasconcelos-, pero la vida misma de la revista depende sobre todo de los discípulos de Antonio Caso: García Máynez, Samuel Ramos y Francisco Larroyo, a quienes hay que agregar el nombre de Juan Hernández Luna, secretario de la publicación y en realidad responsable de ella durante sus últimos diez años. No obstante que García Máynez volvió a la dirección de Filosofía y Letras en 1947, después de Agustín Yáñez, y permaneció en ella durante un largo periodo -cuarenta y tres de los sesenta y nueve números que constituyen la serie completa se publicaron bajo su dirección-, no impuso sus preferencias filosóficas y los temas dominantes de la revista tienen que ser explicados por otros motivos.

Desde sus orígenes, Filosofía y Letras respondía a un impulso propio, en cuya fuerza contaron en primer término los profesores españoles, transterrados en México desde 1938 y 1939. La aparición de la revista coincide, por tanto, con los años en que García Bacca permaneció en México, ligado a la Facultad; con los escasos años de docencia en ella de Joaquín Xirau, José Medina, Luis Recaséns y Juan Roura; con el inicio de la carrera universitaria de Nicol y los primeros años de enseñanzas de Gaos. Primeros años de Gaos dedicados ante 
todo a la historia de la filosofía griega, medieval, a los comienzos de la moderna y a los temas americanos - conquistadores y cronistas. Pero también al estudio de autores de lengua española de los siglos recientes; y a la explicación en clase, en varios semestres sucesivos, de El sery el tiempo.

A la influencia de este grupo y a los mexicanos de las generaciones ya nombradas, hay que sumar los últimos discípulos de Caso que estuvieron también cerca de Gaos: Manuel Cabrera y Antonio Gómez Robledo; pero sobre todo a Edmundo O'Gorman y a Leopoldo Zea, los discípulos de los primeros años y a la vez asiduos colaboradores de la revista. En sus diecisiete años, la revista pudo recibir todavía a dos de las generaciones siguientes de alumnos de Gaos: la de los hiperiones y la de los hegelianos. De los últimos, Filosofíay Letras apenas tuvo ocasión de publicar los primeros ensayos, al comenzar la década de los años cincuentas. Pero del grupo Hiperión no sólo publicó los primeros sino que realizó su "lanzamiento filosófico" - si se me permite decirlo de esta manera-, en un número especial casi íntegramente dedicado al existencialismo francés. En ese número colaboraban cinco jóvenes filósofos del Hiperión, a la cabeza de los cuales se publicó un ensayo sobre la ontología de Sartre escrito por García Bacca, el maestro que les había sugerido reunirse como grupo de estudio.

Las actividades públicas del grupo tuvieron siempre repercusión en otras publicaciones, sin excluir los suplementos culturales de los grandes diarios de aquellos años, pero su órgano especializado fue, invariablemente, Filosofía y Letras.

No creo que resulte exagerado decir que el nacimiento y desarrollo del grupo Hiperión, hasta su desintegración en la década de los años cincuentas, coincide con el momento de plenitud de vida de Filosofía y Letras. Son los años de apogeo del existencialismo en México: de Heidegger y Sartre; también los de más señalado interés en el pensamiento hispanoamericano como objeto de estudio; los de mayor asiduidad en publicaciones sobre la historia de las ideas en México y la llamada filosofía del mexicano.

Sin excluir por completo a la fenomenología y al marxismo, las materias dominantes en la revista -descontados los primeros números-, son precisamente las nombradas. Según se observa de una simple lectura de sus índices, no ciertamente de un detenido análisis de contenido. Pero tal vez basta con esta observación para comprender, siquiera parcialmente, la publicación del primer número de Diánoia, su estructura y hasta el tono de la "Presentación" escrita por su primer director.

A partir de 1945, el Centro de Estudios Filosóficos se separó de la Facultad de Filosofía y empezó a funcionar con rango de Instituto. Su director, García Máynez, quien había fundado Filosofía y Letras en 1941 como órgano de la Facultad, se mantuvo también como director de la revista hasta diciembre de 
1952, en que la entregó a Salvador Azuela, en esa fecha a cargo de la dirección de la Facultad. Para entonces, la revista, que en sus entregas iniciales se imprimía con puntualidad en cuadernos que aparecían cada tres meses y ofrecía en el número cuatro de cada año los índices anuales, había acumulado retrasos y empezado a sumar sus cuadernos en dos volúmenes anuales. Pero desde 1955 todas sus entregas fueran anuales, en gruesos tomos que en sus números anunciaban la acumulación de los cuadernos de enero a diciembre, como si anticiparan la necesidad de convertirse en anuario.

Desde que García Máynez entregó la dirección de la revista, a fines de 1952, se empeñó en la idea de una nueva publicación especializada en filosofía y con carácter internacional pero esta vez como órgano del Centro de Estudios Filosóficos. La concibió, probablemente en diálogo con Eduardo Nicol, a la manera de los voluminosos anuarios alemanes, en especial el Jahrbuch de Husserl. Nicol había sido el primer secretario de Filosofía y Letras, y ahora fue invitado como director de Diánoia, la nueva publicación, cuya primera entrega apareció en 1955. Tres años después dejó de publicarse Filosofía y Letras.

Para marcar la dependencia de Diánoia respecto del Centro y, probablemente, su reserva frente al núcleo mayor de los profesores jóvenes de la Facultad, su contenido se dividía formalmente en tres partes, además de las secciones de noticias y reseñas. La primera, destinada exclusivamente a los escritos de los miembros del Centro; la segunda, dedicada a los seminarios de la Facultad, es decir, a los trabajos de los profesores responsables de los seminarios y a los producidos bajo su dirección; y la última parte, titulada "estudios monográficos", para recibir colaboraciones ajenas al Centro, preferentemente de filósofos extranjeros, pero también mexicanos.

No voy a entrar siquiera en la lectura de los índices de materias del anuario, ni en sus primeros años ni en los posteriores, porque solamente me he propuesto sugerir la ventaja de realizar ese análisis para marcar el pulso de los cambios de la filosofía en México. Menos todavía me voy a referir al cumplimiento de sus propósitos iniciales, entre otras razones porque algunos años después tuve la responsabilidad de conducirlos y lo he dejado escrito en otro lugar. Pero quiero advertir con toda claridad que la libertad y la apertura intelectual de Diánoia nunca estuvo en cuestión, aunque pudieran haber cambiado en algún punto los criterios de rigor filosófico, porque la variada formación intelectual de los miembros del Centro - tan diversa en edades y generaciones como en orientaciones filosóficas-, garantizaba el equilibrio desde los primeros nombramientos anteriores la publicación del anuario.

Lo que me interesa señalar, a manera de conclusión, apenas con un par de frases finales, es la ventaja de leer con atención la declaración expresa de la 
"Presentación" del primer número de Diánoia, escrita por su director, porque leída sin los antecedentes que he señalado puede parecer extraña y hasta pretenciosa, pero vista a la luz de aquellos es apenas una discreta declaración de guerra. Por supuesto, de guerra filosófica, aunque de ninguna manera los jóvenes de entonces podíamos ver como una guerra justa. Es un pronunciamiento cuyas consecuencias no hay tiempo siquiera de insinuar, pero es exactamente lo que pienso que podría ganar cuerpo -expresado en otros términos que los empleados por su autor hace cuarenta años-, sólo si se funda en el estudio de lo que realmente ha sido Diánoia o, todavía más, en el análisis de los contenidos de estas dos publicaciones filosóficas a que me he referido, que han sido parte principal de la vida intelectual de México, en un buen tramo del siglo que está por terminar. 